\title{
The Presence of Sodium Nitrate in Generator Eluate Decreases the Radiochemical Purity of ${ }^{99} \mathrm{~m}$ Tc-Sestamibi
}

\author{
Thierry Métayé ${ }^{1,2}$, Thierry Rosenberg ${ }^{1}$, Joëlle Guilhot ${ }^{3}$, Marie-Hélène Bouin-Pineau ${ }^{1}$, and Rémy Perdrisot ${ }^{1}$ \\ ${ }^{1}$ Department of Nuclear Medicine and Radiopharmacy, University Hospital, Poitiers, France; ${ }^{2}$ CNRS-FRE 3511, University Hospital, \\ Poitiers, France; and ${ }^{3}$ INSERM-CIC 0802, University Hospital, Poitiers, France
}

\begin{abstract}
A high radiochemical purity $(\mathrm{RCP})$ is recommended for radiopharmaceutical compounds used in the clinical practice of nuclear medicine. However, some preparations of $99 \mathrm{mTc}$-sestamibi contain excess impurities (>6\%). To understand the origin of these impurities, we investigated the effect of sodium nitrate on the RCP of sestamibi preparations by testing eluates from 3 commercially available ${ }^{99 m}$ Tc generators. Methods: The sestamibi kits (Stamicis) were reconstituted with ${ }^{99 m T c}$ eluate from nitrate-containing wet-column (NCWC), nitrate-free wet-column (NFWC), and nitrate-free dry-column (NFDC) generators. Sodium nitrate was $0.05 \mathrm{mg} / \mathrm{mL}$ in eluates from the NCWC generators. The RCP was determined using aluminum oxide sheets as the stationary phase and absolute ethanol as the mobile phase. Succimer, tetrofosmin, oxidronate, exametazine, albumin nanocolloid, and soluble albumin were also tested for their RCP values with eluates from the 3 different ${ }^{99 m}$ Tc generators. Results: The RCP assessment of 99mTc-sestamibi was performed on 127 Stamicis preparations. Significantly lower RCP values were found for Stamicis kits prepared with the NCWC generator than for Stamicis prepared with the NFWC $(P<0.0001)$ and NFDC $(P<0.0001)$ generators. The number of Stamicis preparations with an RCP under $94 \%$ was greater with the NCWC generator (32 of 53 kits) than with the NFDC (2 of 51 kits) or NFWC (0 of 23 kits) generator. Furthermore, the addition of a $0.05 \mathrm{mg} / \mathrm{mL}$ concentration of nitrate in NFWC generator eluates significantly decreased the RCP of the Stamicis preparation. In the absence of nitrate in ${ }^{99 m T c}$ eluate, no difference was observed between the RCP values of Stamicis kits prepared with the NFWC and NFDC generators. The $99 \mathrm{mT}$ Tc impurities generated by nitrates did not modify the quality of myocardial imaging (normal heart-to-lung ratio, 2.2), probably because these impurities are not in the heart field of view. No other tested ${ }^{99 m}$ Tcradiopharmaceutical interfered with nitrates. Conclusion: We recommend using nitrate-free generator eluates in 99mTc-sestamibi preparations to improve the product quality and prevent unnecessary exposure of the patient to radiation.
\end{abstract}

Key Words: $99 \mathrm{~m} T \mathrm{c}-$ sestamibi; radiochemical purity; nitrate; ${ }_{99}^{9} \mathrm{Mo} / 99 \mathrm{mTc}$ generator; myocardial scintigraphy

J Nucl Med Technol 2012; 40:187-193

DOI: 10.2967/jnmt.111.101246

\footnotetext{
Received Nov. 23, 2011; revision accepted Mar. 13, 2012.

For correspondence or reprints contact: Thierry Métayé, Service de Médecine Nucléaire, CHU de Poitiers, BP 577, 86021 Poitiers Cedex, France. E-mail: t.metaye@chu-poitiers.fr

Published online Jul. 7, 2012.

COPYRIGHT @ 2012 by the Society of Nuclear Medicine and Molecular Imaging, Inc.
}

O estamibi labeled with ${ }^{99 \mathrm{~m}} \mathrm{Tc}$ ( ${ }^{99 \mathrm{~m}} \mathrm{Tc}$-2-methoxyisobutylisonitril, or MIBI) is a lipophilic cationic complex originally developed as a myocardial perfusion imaging agent (1-4) and subsequently used for parathyroid (5) and tumor (6) imaging. Ninety-five percent of intracellular $99 \mathrm{~m}$ Tc-sestamibi is retained in the mitochondria. Its uptake involves a passive distribution across plasma and mitochondrial membranes, but its retention depends mainly on the large negative transmembrane potential of mitochondria (7). ${ }^{99 \mathrm{~m}}$ Tc-sestamibi is also a transport substance recognized by the multidrug resistance-related $\mathrm{P}$ glycoprotein, and its tumor cell accumulation is enhanced by inhibition of the efflux transport function. This property provided the basis for clinical studies that investigated the role of ${ }^{99 \mathrm{~m}} \mathrm{Tc}$-sestamibi in predicting the response to chemotherapy in patients with cancer.

The monovalent ${ }^{99 m}$ Tc-sestamibi complex consists of 1 atom of ${ }^{99 \mathrm{~m}} \mathrm{Tc}$ in a $+\mathrm{I}$ oxidation state and 6 molecules of MIBI. According to the product package insert, MIBI is in the form of tetrakis (2-MIBI) copper (I) tetrafluoroborate, and stannous chloride dihydrate is the reducing agent of ${ }^{99 m}$ Tc. A high radiochemical purity (RCP) is recommended to prevent unnecessary exposure of the patient to radiation and to obtain good-quality images without hot spots due to the presence of radioactive impurities.

Several factors such as generator ingrowth time, ${ }^{99 \mathrm{~m}} \mathrm{Tc}$ eluate age, activity amount, and dry- or wet-column generator have been shown to affect the RCP of ${ }^{99 \mathrm{~m}} \mathrm{Tc}$-sestamibi (8-11). Radiolysis of the water was proposed as a possible cause shared by all these factors (12). Effectively, the $\mathrm{H}_{2} \mathrm{O}$ radiolysis that results in the formation of strong oxidizing agents $\left(\mathrm{HO}_{2}, \mathrm{HO}, \mathrm{O}_{2}^{-}, \mathrm{H}_{2} \mathrm{O}_{2}\right)$ produces the oxidation of $\mathrm{Sn}^{2+}$ to $\mathrm{Sn}^{4+}$, prevents the reduction of ${ }^{99 \mathrm{~m}} \mathrm{Tc}$-pertechnetate, and consequently decreases the labeling efficiency of ${ }^{99 m}$ Tc-sestamibi (13). Furthermore, the reducing free radicals also produced by water radiolysis are able to form reduced species of pertechnetate, such as ${ }^{99} \mathrm{~m} \mathrm{TcO}_{4}{ }^{2-}$, which bind more strongly to the alumina column of generators than do pertechnetate ions $\left({ }^{99} \mathrm{mcO}_{4}{ }^{-}\right)(14)$. The negative role of nitrate ions in the liquid-liquid extraction of pertechnetate has been known for several decades (15). In chromatographic technetium generators having relatively high activity levels, secondary effects can substantially reduce the elution yield. This reduction of yield can be mitigated by the use 
of electron-scavenging agents, such as nitrate or nitrite ions (16). However, the presence of nitrates has been claimed to indirectly influence the RCP of a ${ }^{99 \mathrm{~m}} \mathrm{Tc}$-sulfur colloid (17), and more recently, manufacturers have proposed dry-column generators that do not contain nitrates (18).

In this study, we showed that sodium nitrate present in eluates from commercially available generators decreased the RCP of ${ }^{99 m} \mathrm{Tc}$-sestamibi. More than half the RCP values fell below the limit recommended by the manufacturer. Furthermore, this effect was MIBI-specific because no sodium nitrate-induced RCP decrease was observed with other ${ }^{99 m}$ Tc-complexed radiopharmaceutical compounds.

\section{MATERIALS AND METHODS}

\section{Preparation of ${ }^{99 m} \mathrm{Tc}$-Sestamibi}

Sodium ${ }^{99 \mathrm{~m} T c-p e r t e c h n e t a t e}(6-11 \mathrm{GBq}$ in $3 \mathrm{~mL})$, obtained from a nitrate-containing wet-column (NCWC) generator (ElumaticIII; Cisbio International), a nitrate-free wet-column (NFWC) generator (Ultra-TechneKow FM; Covidien plc), or a nitrate-free dry-column (NFDC) generator (Drytec; GE Healthcare), was added to a vial from a Stamicis or Cardiolite kit, as recommended by the manufacturer's instructions (Cisbio International). ${ }^{99 \mathrm{~m}} \mathrm{Tc}$-sestamibi was always prepared with a second elution from a generator having an ingrowth time lower than $24 \mathrm{~h}$, and the ${ }^{99 \mathrm{~m}} \mathrm{Tc}$-eluate was no more than $2 \mathrm{~h}$ old. After 5 upward-downward motions, the preparation was placed in a boiling water bath for $10 \mathrm{~min}$. Then, the vial was removed from the water bath and allowed to cool for 15 min before being diluted with a sodium chloride solution $(0.9 \%, \mathrm{w} / \mathrm{v})$ to $6 \mathrm{~mL}$ for Cardiolite or $10 \mathrm{~mL}$ for Stamicis. The preparation was then ready for quality control and clinical purposes.

\section{RCP Determination in ${ }^{99 m}$ Tc-Sestamibi Preparations}

Thin-layer chromatography (TLC) was performed according to the instructions of the manufacturer. Briefly, $20 \mathrm{~mL}$ of absolute ethanol were placed into a cylindric chromatography tank $(8 \times 10$ $\mathrm{cm})$ and the atmosphere was allowed to saturate for at least $20 \mathrm{~min}$. A drop of $3 \mu \mathrm{L}$ of absolute ethanol was applied $1.5 \mathrm{~cm}$ from the bottom of Baker-flex (Avantor Performance Materials, Inc.) aluminum oxide sheets $(2.5 \times 7.5 \mathrm{~cm}$, provided by Cisbio International), followed by a drop of $3 \mu \mathrm{L}$ of ${ }^{99 \mathrm{~m}} \mathrm{Tc}$-sestamibi placed within the wetted region. The spot was allowed to dry in air, and then the TLC sheet was placed into the chromatography tank. When the solvent front reached $1 \mathrm{~cm}$ from the top, the TLC sheet was removed and dried. The distribution of ${ }^{99 \mathrm{~m}} \mathrm{Tc}$ compounds on the aluminum oxide sheet was determined using a storage phosphor-imaging device (Cyclone; PerkinElmer), which gives an image of the radioactive products after activation of a phosphor screen for $3 \mathrm{~min}$. Data acquisition was analyzed with Optiquan image analysis software (PerkinElmer). The mean position of a line, indicating the limit to discriminate between the radioimpurities (free ${ }^{99 \mathrm{~m}} \mathrm{Tc}$-pertechnetate and hydrolyzed-reduced ${ }^{99 \mathrm{~m}} \mathrm{Tc}$ compounds staying at the origin) and ${ }^{99 \mathrm{~m}} \mathrm{Tc}$-sestamibi (migrating at the solvent front), was drawn at $4 \mathrm{~cm}$ from the bottom of the TLC sheet. The RCP of ${ }^{99 m}$ Tc-sestamibi was expressed as the ratio in percentage of radioactivity of the solvent front divided by total ${ }^{99 \mathrm{~m}} \mathrm{Tc}$ of the TLC sheet. As recommended by the manufacturer, the RCP values should be at least $94 \%$ for clinical application. All values below $94 \%$ were measured in triplicate to improve the accuracy of the test.

This TLC method detected impurities A (free ${ }^{99 \mathrm{~m}} \mathrm{Tc}$-pertechnetate) and B (hydrolyzed-reduced ${ }^{99 \mathrm{~m}} \mathrm{Tc}$ compounds) but not im- purity C ( ${ }^{99 \mathrm{~m}} \mathrm{Tc}$-isonitrile complex with a methyl propene group), as mentioned in the European Pharmacopoeia (19). The other quality specifications (organoleptic characters, $\mathrm{pH}$, or $\gamma$-spectrometry) were in conformity with the European Pharmacopoeia.

\section{Addition of Sodium Nitrate to Generator Eluates}

According to the manufacturer's package inserts, the sodium nitrate concentration is $0.05 \mathrm{mg} / \mathrm{mL}$ in NCWC generator eluates, and the other 2 generators, NFWC and NFDC, are eluted with a nitratefree isotonic saline solution.

Sodium nitrate (BioUltra; Sigma), ranging from 0.05 to $0.5 \mathrm{mg} / \mathrm{mL}$, was mixed with sodium ${ }^{99 \mathrm{~m}}$ Tc-pertechnetate $(5-6 \mathrm{GBq}$ in a $3-\mathrm{mL}$ final volume) obtained from a NFWC ${ }^{99} \mathrm{Mo} /{ }^{99 \mathrm{~m}} \mathrm{Tc}$ generator. Then, the radioactivity together with nitrate was added to a vial from a Stamicis kit and the preparation was placed in a boiling water bath for $10 \mathrm{~min}$. The vial was removed from the water bath and allowed to cool for $15 \mathrm{~min}$ before being diluted to $6 \mathrm{~mL}$ with a sodium chloride solution $(0.9 \%, w / v)$. An aliquot of $0.1 \mathrm{~mL}$ was taken to test the RCP of the preparation in triplicate.

\section{RCP Determination in ${ }^{99 m}$ Tc-Radiopharmaceutical Preparations}

The RCP of the ${ }^{99 \mathrm{~m}} \mathrm{Tc}$-succimer (Renocis; Cisbio International) and ${ }^{99 \mathrm{~m} T c-h u m a n}$ albumin nanocolloid preparations (Nanocoll; GE Healthcare) was determined using a narrow strip of chromatography paper (number $1,2.5 \times 12.5 \mathrm{~cm}$; Whatman International Ltd.) as the stationary phase and acetone as the mobile phase.

The RCP of the ${ }^{99 \mathrm{~m}} \mathrm{Tc}$-tetrofosmin preparations (Myoview; GE Healthcare) was determined using an instant TLC plate impregnated with silica gel (ITLC/SG, $2.5 \times 10 \mathrm{~cm}$; Pall Corp.) as the stationary phase and 2-butanone as the mobile phase (20). Another method used a narrow strip of glass microfiber chromatography paper impregnated with silicic acid $(2 \times 11 \mathrm{~cm}$; Varian SA) as the stationary phase and acetone/dichloromethane $(65 / 35, \mathrm{v} / \mathrm{v})$ as the mobile phase.

The RCP of the ${ }^{99 m} \mathrm{Tc}$-oxidronate preparations (TechneScan HDP; Covidien plc) was determined using 2 separated TLCs with ITLC/SG strips $(2.5 \times 10 \mathrm{~cm}$; Pall Corp. or Varian SA $)$ as the stationary phase and acetone and sodium acetate $(1 \mathrm{M})$ as the mobile phases.

The RCP of the ${ }^{99 \mathrm{~m}} \mathrm{Tc}$-exametazime preparations (Cerestab; GE Healthcare) was determined using 2 separated TLCs with ITLC/SG strips $(2 \times 15 \mathrm{~cm}$; Pall Corp. $)$ as the stationary phase and 2-butanone and $\mathrm{NaCl} 0.9 \%$ as the mobile phases. Another method used the same mobile phases but chromatography paper $(2 \times 15 \mathrm{~cm}$; Varian SA) instead of ITLC/SG as the stationary phase.

The RCP of the ${ }^{99 m} \mathrm{Tc}-$ human soluble albumin preparations (Vasculocis; Cisbio International) was determined using a narrow strip of chromatography paper (number $1,2.5 \times 10 \mathrm{~cm}$; Whatman International Ltd.) as the stationary phase and methanol/water (80/20, $\mathrm{v} / \mathrm{v})$ as the mobile phase.

\section{Statistical Analysis}

The nonparametric Kruskal-Wallis and Wilcoxon rank-sum tests were used for comparison of the RCP data among groups of different ${ }^{99 \mathrm{~m}} \mathrm{Tc}$-radiopharmaceutical preparations. The RCPs of ${ }^{99 m}$ Tc-sestamibi at different levels of nitrate concentrations and the heart-to-liver ratios were compared with the control using the Student $t$ test. All $P$ values were 2 -sided, and the type I error was set at $5 \%$. Statistical analyses were performed using SAS software, version 9.2 (SAS Institute). 
TABLE 1

Sample Characteristics of RCP Measurements in Different 99mTc-Sestamibi Preparations

\begin{tabular}{lcccccc}
\hline 99mTc-sestamibi preparation & Preparation number & Median (\%) & Minimum (\%) & Maximum (\%) & Mean (\%) & SD (\%) \\
\hline CardCis $^{*}$ & 56 & 95.25 & 89.10 & 97.90 & 94.93 \\
StamCis $^{\dagger}$ & 53 & 93.40 & 81.30 & 97.40 & 92.75 \\
StamGE $^{\ddagger}$ & 51 & 96.80 & 89.60 & 98.40 & 3.55 \\
StamCov\$ & 23 & 96.60 & 94.90 & 98.90 & 96.72 & 1.31 \\
\end{tabular}

${ }^{\star}$ Cardiolite kit prepared with ${ }^{99 m}$ Tc eluate from NCWC generator.

${ }^{\dagger}$ Stamicis kit prepared with ${ }^{99 \mathrm{~m} T c}$ eluate from NCWC generator.

${ }^{\ddagger}$ Stamicis kit prepared with ${ }^{99 \mathrm{~m} T c}$ eluate from NFDC generator.

$\S$ Stamicis kit prepared with ${ }^{99 m T c}$ eluate from NFWC generator.

\section{RESULTS}

The RCP assessment of ${ }^{99 \mathrm{~m}} \mathrm{Tc}$-sestamibi was performed on 127 Stamicis and 56 Cardiolite preparations. The Cardiolite kits were prepared with eluates from the NCWC generator (CardCis), and the Stamicis kits were prepared with eluates from the NCWC (StamCis), NFDC (StamGE), and NFWC (StamCov) generators. Table 1 presents sample characteristics, including the number of kits and the median, minimum, maximum, mean, and SD of the RCP values. Sample distribution appeared quite similar except for StamCis, which had more widely spread data, with an SD $(3.55 \%)$ higher than that for CardCis (1.75\%), StamGE $(1.31 \%)$, or StamCov $(0.94 \%)$. The statistical analysis indicated that the RCP values obtained with StamCis were significantly lower than those obtained with StamGE $(P<0.0001)$ or StamCov $(P<0.0001)$ (Fig. 1$)$. Furthermore, the comparison of RCP values obtained with StamGE (only 2 RCP values of 51 kits were under 94\%) and StamCov (no RCP value was under 94\%) showed no statistical difference. On the other hand, the Cardiolite kits (16 RCP values of 56 kits were under $94 \%$ ) were significantly less affected by eluates from the NCWC generators than were the Stamicis kits (32 RCP values of 53 kits were under $94 \%$, $P<0.0001$ ). Three to 5 different sestamibi batches were tested with each generator. The influence of different factors-such as the presence versus absence of nitrate, wet- versus drycolumn generator, and kit type-on the RCP values is recapitulated in Table 2. Altogether, these results suggest a negative role for nitrates in the Stamicis preparations.

To confirm nitrate effects, we tested whether the addition of sodium nitrate to ${ }^{99 \mathrm{~m}} \mathrm{Tc}$ eluates from the NFWC generator modified the RCP of ${ }^{99 \mathrm{~m}} \mathrm{Tc}$-sestamibi. Clearly, an increase in nitrate concentrations decreased the RCP of ${ }^{99} \mathrm{mc}$-sestamibi preparations from $96.77 \%$ for control to $67.77 \%$ for a $0.5 \mathrm{mg} /$ $\mathrm{mL}$ concentration of nitrate (Fig. 2). Furthermore, a concentration level corresponding to that present in the NCWC generator eluates $(0.05 \mathrm{mg} / \mathrm{mL}$ nitrate) led to a RCP $(94.43 \%)$ lower than that of the control $(P<0.01)$. Myocardial perfusion images of a patient with a poor-RCP ${ }^{99 \mathrm{~m} T c-s e s t a m i b i}$ preparation are presented in Figure 3. Despite the presence of impurities (17.2\%), no image degradation was noted. The heart-to-lung ratio of count density (2.22) was relevant for image quality and was comparable to that initially described in healthy volunteers (3). Furthermore, the heart-to-liver ratio (0.61) in Figure 3 was in the range of those obtained for normal-heart scintigraphy with a good-quality ${ }^{99 \mathrm{~m}} \mathrm{Tc}$-sestamibi preparation $(\mathrm{RCP}$ value $>94 \%), 0.55 \pm 0.10(n=8)$. The heart-to-liver ratio of normal-heart scintigraphic images with a poor-quality ${ }^{99 \mathrm{~m}} \mathrm{Tc}$-sestamibi preparation was $0.63 \pm$ $0.13(n=7)$, slightly higher but not significantly different $(P=0.106)$ from ratios for ${ }^{99 \mathrm{~m}} \mathrm{Tc}$-sestamibi preparations with RCP values higher than 94\%. The absence of abnormal organ uptake by the stomach or thyroid ruled out excess free pertechnetate in the Stamicis preparation (Fig. 3).

To investigate whether other radiopharmaceutical compounds were nitrate-sensitive, we measured the RCP of the

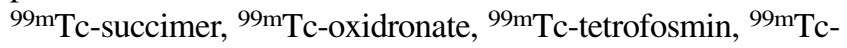
exametazime, ${ }^{99 \mathrm{~m}} \mathrm{Tc}$-albumin nanocolloid, and ${ }^{99 \mathrm{~m} T c-s o l u b l e}$ albumin preparations with the 3 commercially available generators (Table 3). A significant difference was observed

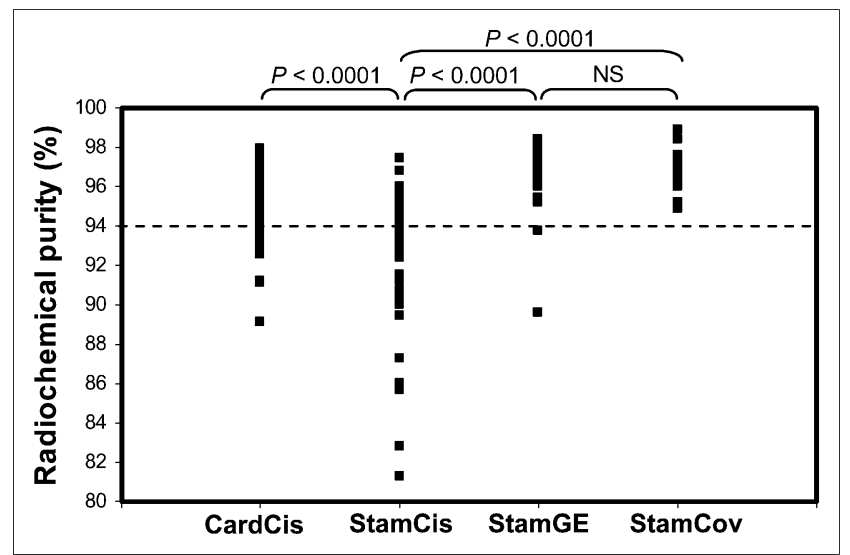

FIGURE 1. Distribution of RCP values of $99 \mathrm{mTc}$-sestamibi preparations using $99 \mathrm{mTc}$-pertechnetate from 3 different generators. Dotted line represents RCP limit (94\%) recommended by manufacturer for clinical application. Number of RCP values under $94 \%$ is $16,32,2$, and 0 for CardCis, StamCis, StamGE, and StamCov, respectively. CardCis $=$ Cardiolite kit prepared with ${ }^{99 m T c}$ eluate from NCWC generator; StamCis = Stamicis kit prepared with ${ }^{99 \mathrm{~m} T c}$ eluate from NCWC generator; StamGE = Stamicis kit prepared with ${ }^{99 \mathrm{~m} T c}$ eluate from NFDC generator; StamCov = Stamicis kit prepared with ${ }^{99 m T c}$ eluate from NFWC generator; NS = not significant. 
TABLE 2

Influence of Different Factors on RCP (mean \pm SD) of ${ }^{99 m}$ Tc-Sestamibi Preparations

\begin{tabular}{|c|c|c|c|c|c|}
\hline Factor & CardCis $^{*}$ & StamCis $^{\dagger}$ & StamGE $\ddagger$ & StamCov§ & $P$ \\
\hline Presence vs. absence of nitrate $(0.05 \mathrm{mg} / \mathrm{mL})$ & & $\begin{array}{l}92.54 \pm 3.55 \\
92.54 \pm 3.55\end{array}$ & $96.72 \pm 1.31$ & $96.68 \pm 0.94$ & $\begin{array}{l}<0.0001 \\
<0.0001\end{array}$ \\
\hline Wet vs. dry column (absence of nitrate) & & & $96.72 \pm 1.31$ & $96.68 \pm 0.94$ & NS \\
\hline Kit type & $94.93 \pm 1.75$ & $92.54 \pm 3.55$ & & & $<0.0001$ \\
\hline
\end{tabular}

${ }^{*}$ Cardiolite kit prepared with ${ }^{99 m}$ Tc eluate from NCWC generator.

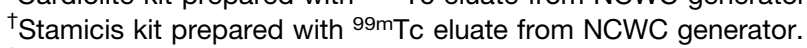

${ }^{\ddagger}$ Stamicis kit prepared with ${ }^{99 m}$ Tc eluate from NFDC generator.

$\S$ Stamicis kit prepared with ${ }^{99 \mathrm{~m} T c}$ eluate from NFWC generator.

$\mathrm{NS}=$ not significant.

only for ${ }^{99 \mathrm{~m}}$ Tc-tetrofosmin method $1(P=0.0002)$, and a tendency was observed for ${ }^{99 \mathrm{~m}}$ Tc-exametazime method $1(P=$ 0.0532). Unexpectedly, the presence of nitrates in eluates from the NCWC generators increased rather than decreased the RCP of ${ }^{99 m}$ Tc-tetrofosmin and ${ }^{99 m}$ Tc-exametazime. However, the slight changes observed were without clinical consequence on image quality.

\section{DISCUSSION}

The European Pharmacopoeia mentions 3 radiochemical impurities detected with 3 different methods (reversedphase TLC, paper chromatography, and HPLC) for the ${ }^{99 \mathrm{~m}}$ Tc-sestamibi preparation (19). These reference methods are rather time-consuming and cumbersome without adding value for daily practice. We measured the RCP of ${ }^{99 m}$ Tc-sestamibi with a TLC method according to the manufacturer's instructions, which were easier to perform than the official methods proposed by the European Pharmacopoeia.

In this study, we analyzed the effects of sodium nitrate on ${ }^{99 m}$ Tc-sestamibi synthesis. First, the use of nitrate-containing generator eluates gave unacceptable RCPs for the Stamicis preparations when compared with RCPs from preparations reconstituted with nitrate-free generator eluates. Second, the addition of nitrates at the concentration present in the NCWC generators significantly decreased the RCP of a nitrate-free Stamicis preparation. Third, the Cardiolite kits showed a failure rate that was substantial but lower than that for the Stamicis kits when the sestamibi preparations were reconstituted with a nitrate-containing generator eluate. Fourth, no significant difference was observed between the RCP values of Stamicis kits prepared with ${ }^{99 \mathrm{~m}} \mathrm{Tc}$ eluates from a dry-column generator, compared with those obtained from a wet-column generator (Fig. 1, StamGE and StamCov), suggesting that water radiolysis was not involved in the formation of Stamicis impurities. Although the NFWC generators are delivered as dry-column generators, they are considered wet-column generators because excess physiologic saline solution stays in the column after the first elution. Taken together, our results demonstrate that the presence of nitrates in ${ }^{99 m} \mathrm{Tc}$ eluates is the main factor responsible for the RCP failure in the preparation of Stamicis kits.
Sodium nitrate is an oxidizing agent present in ${ }^{99 \mathrm{~m}} \mathrm{Tc}$ eluates to protect pertechnetate reduction caused by the electrons emitted by ${ }^{99} \mathrm{Mo}$ and to react with strong reducing agents, such as aqueous electron or hydrogen radicals, provided by the water radiolysis of wet-column generators. In the Stamicis kit preparations, sodium nitrate might also oxidize $\mathrm{Sn}^{2+}$ to $\mathrm{Sn}^{4+}$ and hinder the full reduction of

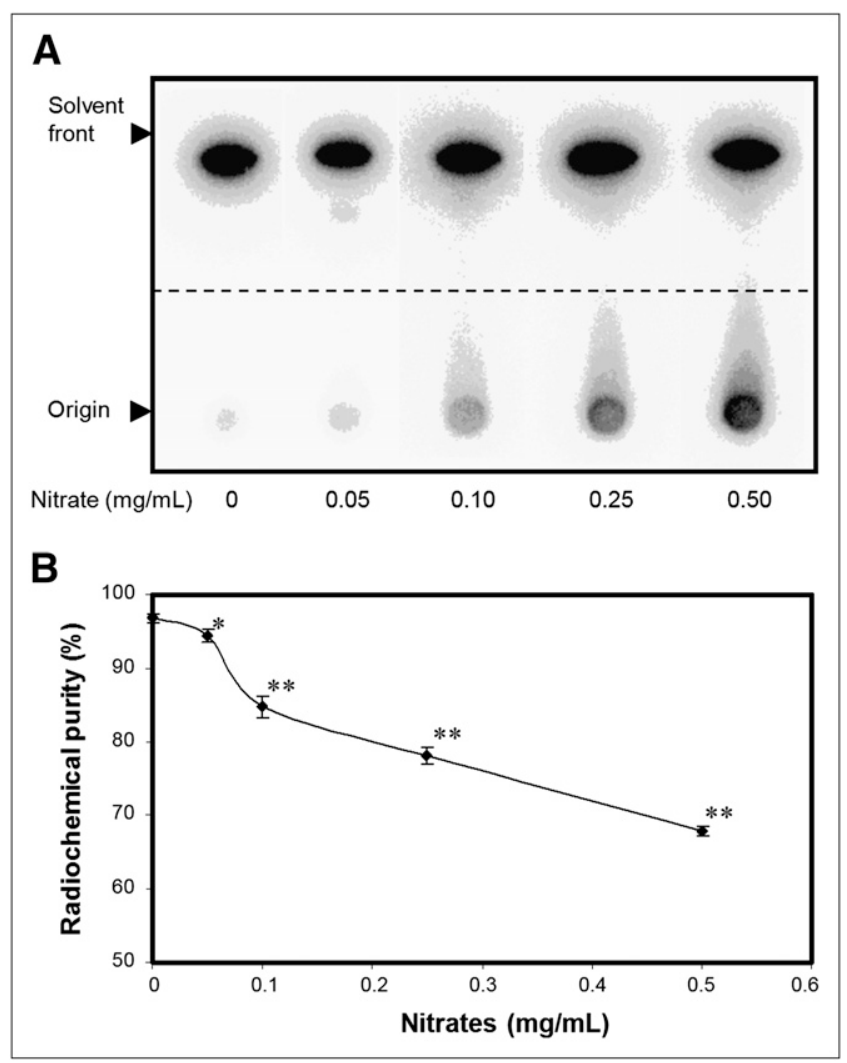

FIGURE 2. Effect of nitrate concentrations on RCP of Stamicis preparations. (A) TLC of $99 \mathrm{mTC}$-sestamibi using Baker-flex aluminum oxide sheet as stationary phase and absolute ethanol as mobile phase. Dotted line indicates cutting position to determine percentages of $99 \mathrm{mTc}$-sestamibi and radioimpurity fractions. (B) Nitrate-purity curve of RCP values obtained in A. Data are mean \pm SD of triplicate RCP determinations. ${ }^{\star} P<0.01$. ${ }^{\star \star} P \leq 0.001$. A color version of this figure is available as a supplemental file at http://tech.snmjournals.org. 

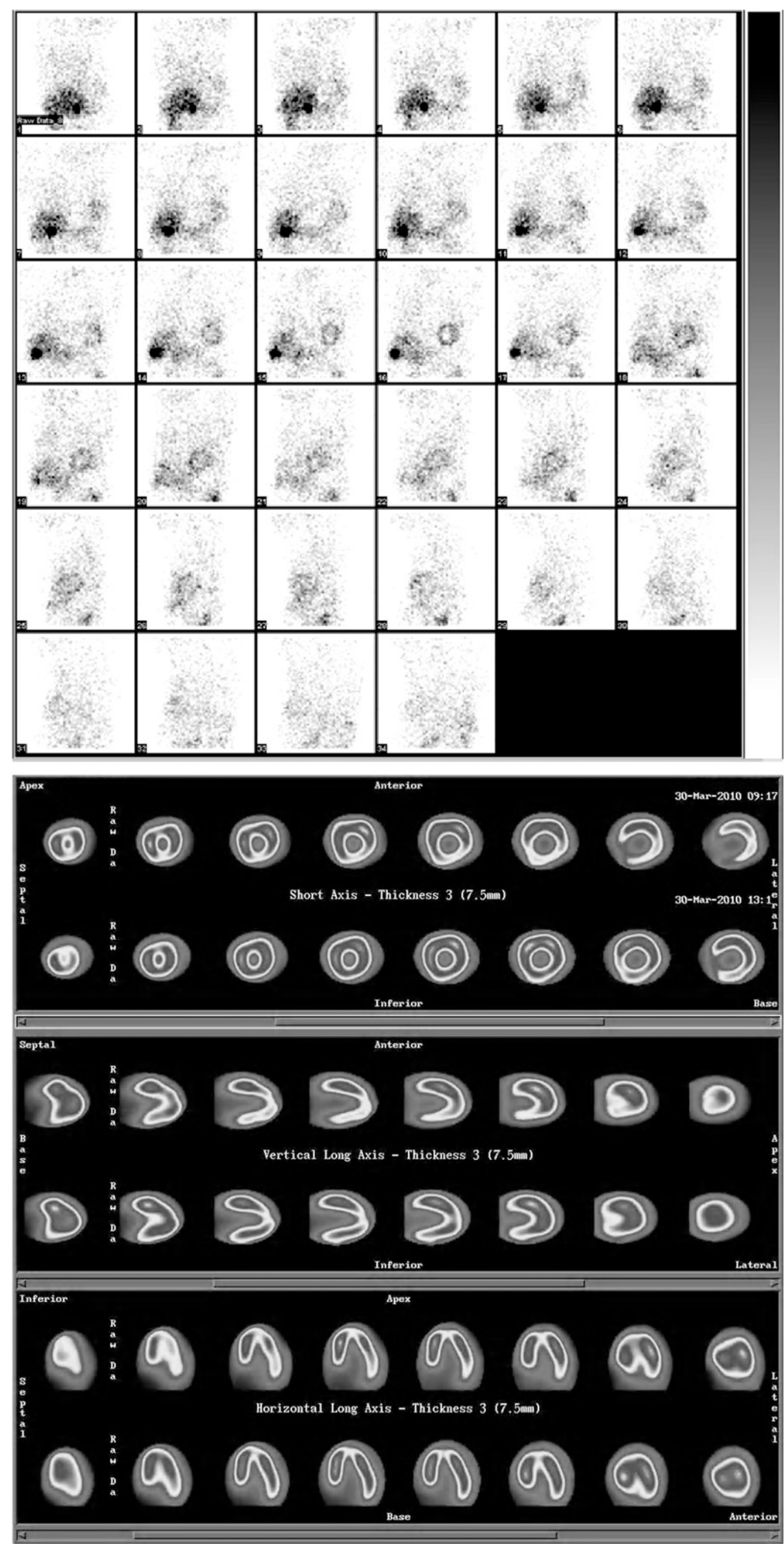

FIGURE 3. Myocardial perfusion images with $99 \mathrm{mTc}$-sestamibi prepared with wetcolumn generator eluate containing nitrates $(0.05 \mathrm{mg} / \mathrm{mL})$. RCP of Stamicis preparation was $82.8 \%$. Raw data and tomographic slices are presented in upper and lower image series, respectively. Stress images are displayed on top rows and rest images on bottom rows. Sternal region and hepatic dome were used as regions of interest to determine heart-tolung and heart-to-liver ratios, respectively. Heart-to-lung ratio was 2.2, and heart-toliver ratio was 0.61 . A color version of this figure is available as a supplemental file at http://tech.snmjournals. org. 
TABLE 3

Influence of ${ }^{99 m T c}$ Generator Eluates on RCP Values of Different Radiopharmaceuticals

\begin{tabular}{|c|c|c|c|c|c|c|c|c|}
\hline \multirow[b]{2}{*}{ Radiopharmaceutical } & \multirow[b]{2}{*}{ Method } & \multicolumn{2}{|c|}{ NCWC generator } & \multicolumn{2}{|c|}{ NFDC generator } & \multicolumn{2}{|c|}{ NFWC generator } & \multirow[b]{2}{*}{$P$} \\
\hline & & $N$ & Mean $\pm \mathrm{SD}$ & $N$ & Mean $\pm \mathrm{SD}$ & $N$ & Mean $\pm S D$ & \\
\hline 99mTc-succimer & & 31 & $99.77 \pm 0.28$ & 19 & $99.82 \pm 0.21$ & 9 & $99.49 \pm 0.99$ & NS \\
\hline \multirow[t]{2}{*}{ 99mTc-oxidronate } & 1 & 31 & $97.65 \pm 0.70$ & NT & NT & 31 & $97.54 \pm 0.85$ & NS \\
\hline & 2 & 31 & $98.09 \pm 1.22$ & 31 & $98.14 \pm 0.91$ & NT & NT & NS \\
\hline \multirow[t]{2}{*}{ 99mTc-tetrofosmin } & 1 & 31 & $95.39 \pm 1.32$ & NT & NT & 31 & $94.13 \pm 0.89$ & 0.0002 \\
\hline & 2 & 31 & $98.28 \pm 0.54$ & 31 & $98.14 \pm 0.88$ & NT & NT & NS \\
\hline \multirow[t]{2}{*}{ 99mTc-exametazime } & 1 & 31 & $90.51 \pm 2.25$ & NT & NT & 31 & $89.51 \pm 2.28$ & 0.0532 \\
\hline & 2 & 31 & $91.33 \pm 1.92$ & 31 & $90.39 \pm 2.13$ & NT & NT & NS \\
\hline 99mTc-albumin nanocolloid & & 32 & $99.88 \pm 0.14$ & 22 & $99.84 \pm 0.16$ & 32 & $99.86 \pm 0.18$ & NS \\
\hline 99mTc-soluble albumin & & 35 & $97.31 \pm 4.38$ & 38 & $97.89 \pm 1.36$ & NT & NT & NS \\
\hline
\end{tabular}

$\mathrm{NT}=$ not tested; NS = not significant.

For ${ }^{99 m}$ Tc-oxidronate, method 1 used ITLC/SG strips from Varian SA and method 2 used ITLC/SG strips from Pall Corp. For 99mTctetrofosmin, method 1 used chromatography paper from Varian SA and method 2 used ITLC/SG strips from Pall Corp. For 99mTc-exametazime, method 1 used chromatography paper from Varian SA and method 2 used ITLC/SG strips from Pall Corp. $P$ values compared data from NCWC generators with those obtained from NFDC or NFWC generators.

pertechnetate ions, preventing the formation of a complex between reduced ${ }^{99 \mathrm{~m}} \mathrm{Tc}(+\mathrm{I}$ oxidation state) and 6 molecules of MIBI. According to Varelis et al. (10), the major radiochemical impurity in ${ }^{99 \mathrm{~m}} \mathrm{Tc}$-sestamibi preparations from fractionated Cardiolite kits was found on HPLC to be a ${ }^{99 m} \mathrm{Tc}$-isonitrile complex or a derivative different from sodium ${ }^{99} \mathrm{~m}$ Tc-pertechnetate, ${ }^{99} \mathrm{~m}$ Tc-cysteine, and ${ }^{99} \mathrm{~m} \mathrm{Tc}-$ citrate. The last 2 compounds could conceivably be produced by chelation of ${ }^{99 \mathrm{~m}} \mathrm{Tc}$ with cysteine hydrochloride and sodium citrate present in the Cardiolite and Stamicis kits $(21,22)$. Furthermore, rat scintigraphic imaging with the Cardiolite impurity ( ${ }^{99 \mathrm{~m}} \mathrm{Tc}$-isonitrile complex) showed no heart uptake and rapid clearance through the kidneys. This finding agrees with scintigraphic images of the human heart, for which radioimpurities do not interfere with image quality, suggesting that the behavior of both the impurities described by Varelis et al. (10) and those in our study is similar.

The significant difference in RCP values between the Cardiolite preparations and its generic medicine, the Stamicis preparation, is not easy to explain. However, the use of highdissolved-oxygen standard saline has been described as an artifact in the stability of radiopharmaceuticals because dissolved oxygen promotes formation of peroxide and hydroperoxy radicals (23). Thus, a greater dilution volume with standard saline for the Stamicis preparations compared with Cardiolite might be an explanation for the higher RCP failure rate observed with Stamicis.

Why is ${ }^{99 m}$ Tc-sestamibi the only radiopharmaceutical compound interfering with nitrates in its labeling reaction? One possible reason would be the low oxidation state of technetium $(+\mathrm{I})$ in the ${ }^{99 \mathrm{~m}} \mathrm{Tc}$-sestamibi complex formed from the Tc (VII) precursor and the great number of potential ligands that would stabilize the intermediate oxidation states, including the isonitrile, chloride, mannitol, cysteine, citrate, and oxo ligands (24). The pathway to the synthesis of ${ }^{99 \mathrm{~m}}$ Tc-sestamibi involves 7 intermediates and at least 2 steps.
The first step is the lowering of the oxidation state of technetium by the initial coordination of cysteine, and the second step is the direct coordination of isonitrile. It is the intermediates in this second step that require thermal energy to produce ${ }^{99 \mathrm{~m}} \mathrm{Tc}$-sestamibi. In comparison, the oxidation states of technetium in other radiopharmaceutical compounds are IV or V, the number of intermediates is lower, and the synthesis needs no heating. In the ${ }^{99 \mathrm{~m}} \mathrm{Tc}$-sestamibi preparation, sodium nitrate probably blocks an intermediate complex, but determination of the exact chemical nature of the impurities requires further investigation.

\section{CONCLUSION}

We showed that sodium nitrate present in eluates of NCWC generators increased the RCP failure rate of ${ }^{99 \mathrm{~m}} \mathrm{Tc}$-sestamibi preparations. This effect was independent of the generator characteristics - wet or dry column-and did not affect other radiopharmaceutical compounds. The radiochemical impurities generated by nitrates did not modify the interpretation of myocardial perfusion scintigraphy, probably because these impurities are not in the heart field of view. However, we recommend using nitrate-free generator eluates in the ${ }^{99 \mathrm{~m}} \mathrm{Tc}$-sestamibi preparation to improve the product quality and to reduce unnecessary exposure of the patient to radiation.

\section{ACKNOWLEDGMENTS}

We are grateful to all the nuclear medicine technologists and medical staff from the Department of Nuclear Medicine of Poitiers University Hospital for their expert assistance. No potential conflict of interest relevant to this article was reported.

\section{REFERENCES}

1. McKusick K, Bellar G, Berman D, et al. Initial clinical results with ${ }^{99 \mathrm{~m}} \mathrm{Tc}$ methoxy isobutyl isonitrile [abstract]. J Am Coll Cardiol. 1987;9(suppl):28A. 
2. Taillefer R, Dupras G, Sporn V, et al. Myocardial perfusion imaging with a new radiotracer, technetium-99m-hexamibi (methoxy isobutyl isonitrile): comparison with thallium-201 imaging. Clin Nucl Med. 1989;14:89-96.

3. Wackers FJTh, Berman DS, Maddahi J, et al. Technetium-99m hexakis 2-methoxyisobutyl isonitrile: human biodistribution, dosimetry, safety, and preliminary comparison to thallium-201 for myocardial perfusion imaging. J Nucl Med. 1989;30:301-311.

4. Mousa SA, Cooney JM, Williams SJ. Relationship between regional myocardial blood flow and the distribution of ${ }^{99 \mathrm{~m}} \mathrm{Tc}$-sestamibi in the presence of total coronary artery occlusion. Am Heart J. 1990;119:842-847.

5. Coakley AJ, Kettle AG, Wells CP, O'Doherty MJ, Collins RE. 99Tcm sestamibi: a new agent for parathyroid imaging. Nucl Med Commun. 1989;10:791794.

6. Burak Z, Argon M, Memiş A, et al. Evaluation of palpable breast masses with 99Tcm-MIBI: a comparative study with mammography and ultrasonography. Nucl Med Commun. 1994;15:604-612.

7. Maublant J. ${ }^{99 \mathrm{~m}} \mathrm{Tc}-\mathrm{MIBI}$. In: Comet M, Vidal M, eds. Radiopharmaceutiques: Chimie des Radiotraceurs et Applications Biologiques. Grenoble, France: Presses Universitaires de Grenoble; 1998:467-478.

8. Herold TJ, Wilson ME, Hung JC, Gibbons RJ. Generator eluate effects on the labelling efficiency of Tc-99m sestamibi kits [abstract]. J Nucl Med. 1993;34 (suppl):148P.

9. Hung JC, Herold TJ, Wilson ME, Gibbons RJ. Generator eluate effects on the labeling efficiency of 99mTc-sestamibi. Nucl Med Biol. 1995;22:949-951.

10. Varelis P, Parkes SL, Poot MT. The influence of generator eluate on the radiochemical purity of 99Tcm-sestamibi prepared using fractionated Cardiolite kits. Nucl Med Commun. 1998;19:615-623.

11. Norenberg JP, Vaidya MP, Hladik WB III, et al. The effect of selected preparation variables on the radiochemical purity of ${ }^{99 \mathrm{~m} T c-s e s t a m i b i . ~ J ~ N u c l ~ M e d ~ T e c h n o l . ~}$ 2005;33:34-41.

12. Hung JC, Herold TJ, Gibbons RJ. Optimal conditions of ${ }^{99 \mathrm{~m}} \mathrm{Tc}$ eluate for the radiolabeling of ${ }^{99 \mathrm{~m}}$ Tc-sestamibi. Nucl Med Biol. 1996;23:599-603.
13. Gardès-Albert M. Chimie sous rayonnement. In: Tubiana M, ed. Radiobiologie, Radiothérapie et Radioprotection: Bases Fondamentales. Paris, France: Hermann Médecine; 2008:40-73.

14. Steigman J, Eckelman WC. The Chemistry of Technetium in Medicine. Washington, DC: National Academy Press; 1992.

15. Rimshaw SJ, Malling GF. Solvent extraction of technetium and rhenium with pyridine or methyl-substituted pyridine derivatives from alkaline media. Anal Chem. 1961;33:751-754.

16. Molter M, Pütter D, inventors; Hoechst AG, assignee. Process to separate technetium-99m from molybdenum-99. European patent 0,014,957. September 3, 1980.

17. Dumortier AG, Jeghers OM, Decostre P, Fallais CJ. Indirect influence of sodium nitrate on the radiochemical purity of a Tc-sulfur colloid. Int J Appl Radiat Isot. 1974;25:189-191.

18. Druce M, Anderson PA. Technetium- $99 \mathrm{~m}$ generator for the $21 \mathrm{st}$ century. In: Stevenson NR ed. Isotope Production and Applications in the 21st Century: Proceedings of the 3rd International Conference on Isotopes. Vancouver, Canada: World Scientific; 1999:74-76.

19. Technetium $\left({ }^{99 \mathrm{~m}} \mathrm{Tc}\right)$ sestamibi injection. European Pharmacopoeia. 6th ed. 2008:1119-1120.

20. Métayé T, Desmarquet M, Rosenberg T, Guilhot J, Bouin-Pineau MH. Rapid quality control for testing the radiochemical purity of $99 \mathrm{Tc}(\mathrm{m})$-tetrofosmin. Nucl Med Commun. 2001;22:1139-1144.

21. Wang AY, Liu RS. Evaluation of the biodistribution and in vivo biochemistry of ${ }^{99 m}$ Tc-cysteine and ${ }^{99} / 99 \mathrm{~m}$ Tc-cysteine complexes: a potential renal imaging agent. Nucl Med Biol. 1995;22:937-942.

22. Ercan MT, Aras T, Unlenen E, Unlü M, Unsal IS, Hasçelik Z. ${ }^{99 \mathrm{~m}}$ Tc-citrate versus ${ }^{67} \mathrm{Ga}$-citrate for the scintigraphic visualization of inflammatory lesions. Nucl Med Biol. 1993;20:881-887.

23. Hung JC, Ponto JA, Hammes RJ. Radiopharmaceutical-related pitfalls and artefacts. Semin Nucl Med. 1996;26:208-255.

24. Parrott SJ, Carroll TR. Determination of the chemistry of a Cardiolite kit [abstract]. J Nucl Med. 1994;35(suppl):138P. 